\title{
Some Cases of New Growths in Fish.
}

\author{
By \\ G. Harold Drew, \\ Beit Memorial Research Fellow.
}

With Plate IV.

TABLE OF CONTENTS.

A Fibro-sarcoma of Raia macrorhynchus An Endothelioma of an Eel (Conger vulgaris)

A Fibro-sarcoma of a Plaice (Pleuronectes platessa) . $\quad . \quad$. $\quad .284$

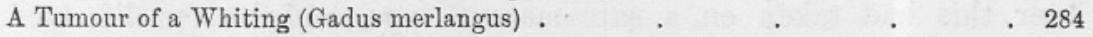

Haemangiomata of a Spotted Ray (Raia maculata) and of a Gurnard (Trigla lineata) 285

A pigmented Tumour of a Mackerel (Scomber scomber) of inflammatory origin $\quad$. 285

\section{A FIBRO-SARCOMA OF RAIA MACRORHYNCHUS.}

THIs specimen, obtained from one of the Plymouth trawlers, consisted of a large tumour on the dorsal surface, near the left angle of the fin (see Figs. 1 and 2). Only part of the fish was available for examination, so the presence of metastases and other details could not be determined.

The tumour was roughly circular, measuring about 4 inches in diameter, and was elevated above the skin about $1_{\frac{1}{4}}^{\frac{1}{4}}$ inches. It consisted of a broad central pedicle, hard and fibrous and white in colour, surrounded by a broad cauliflower-like mass of a greyish colour, and of much softer consistency than the central mass. This peripheral part of the tumour was covered by a very thin layer of epithelium which lined the outside of the pedicle and was continuous with the epidermis; it extended into all the folds and hollows of the outer papilliform portion of the tumour, but was absent over the flat upper extremity of the pedicle.

An incision made along a diameter of the growth, and carried down into the tissues of the fish, revealed the fact that the tumour arose from the fibrous perichondrium of one of the fin rays. The central mass consisted of closely packed strands of white fibrous tissue of pearly whiteness, running at first in a direction perpendicular to the skin, and then branching out into the surrounding ring of softer tissue.

Sections of the pedicle showed that it consisted of strands of typical white fibrous tissue ; these were closely packed, but a few small round cells, having a somewhat indefinite nucleus, and little or no cytoplasm, were present between the fibres, and occasionally the elongated nuclei of 
the fibrous tissue cells were observable. Sections of the softer peripheral part of the tumour (Fig. 3) showed irregular loosely packed strands of fibrous tissue containing a few elongated nuclei, and large numbers of the small round cells, described above, often occurring in small aggregations between the strands and fibrils of the fibrous tissue stroma. No definite blood-vessels were present, and blood spaces were rare. Superficially this portion of the growth was entirely covered by a single layer of squamous epithelial cells continuous with the epidermis, but there was nothing in this covering corresponding to the other layers of the skin, and no denticles or mucous glands were present.

It would thus appear that the tumour had been originally a simple fibroma arising from the perichondrium of one of the fin rays, and that later this had taken on a sarcomatous type, and had proliferated freely. Considering the very poor blood supply to the peripheral part of the tumour, the fact that this portion should have become of a distinctly sarcomatous nature, its evident free proliferation, and the absence of necrosis, is remarkable.

\section{AN ENDOTHELIOMA OF AN EEL (CONGER VULGARIS).}

This tumour was found on an eel caught at Plymouth. The fish was an immature female, about four feet long, and appeared in good condition.

The growth consisted of a nearly spherical mass in the region of the basi-hyal; it was about 1 inch in diameter and protruded about $1 \frac{1}{4}$ inches from the level of the skin. The tumour was of a whitish colour, but in parts was somewhat haemorrhagic; the surface was rough and irregular, with, in places, minute pits lined with thickened epidermis. The skin was not continuous over the surface of the growth, but gradually thinned away at its margin until the junction of skin and tumour became indistinguishable and inseparable. The outer portion of the growth was moderately soft, but it felt as though there was a hard central part which was continuous with the basi-hyal; the arrangement suggested a considerable outgrowth of thickening of the basi-hyal in an anterior direction, and that this outgrowth had penetrated through the skin and become closely adherent to it at the margin. An incision made along a diameter of the tumour showed a central bone-like core, apparently formed by an outgrowth of the basi-hyal, and small areas of highly vascular tissue interspersed among patches of white fibrous tissue, in some of which deposition of lime salts was taking place. Other areas appeared semicartilaginous and some seemed myxomatous. 
Microscopic sections presented very varying pictures according to the particular part of the tumour from which they were taken. The central part of the mass, after decalcification, could be recognised as consisting of fibrous tissue in which a considerable deposition of lime salts had taken place; this mass surrounded and merged into the bony tissue of the basi-hyal, and was penetrated in all directions by narrow blood spaces. These spaces were filled with blood corpuscles and rounded cells with large nuclei and distinct nuceoli; the amount of surrounding cytoplasm varied considerably in different cells, but was seldom great. From the fact that these blood spaces were more plentiful in the outer part of the central mass and did not penetrate to the centre, it would seem probable that the hard fibrous tissue had first been formed and had undergone partial calcification, and that then it had been invaded by the formation of ingrowing capillary blood spaces. Other sections from the softer parts of the tumour showed areas of loose and compact fibrous tissue, and other areas undergoing myxomatous degeneration: blood corpuscles and the rounded cells described above were present in varying numbers in almost every part of the growth. The surface of the marginal part of the tumour was irregularly covered with the cutaneous epithelium which had a tendency to form ingrowths of compact masses of epithelial cells, but did not show signs of becoming epitheliomatous. The more highly cellular portions of the growth presented the appearance shown in Fig. 6. Masses of rounded epithelioid cells were present, and irregular channels containing blood corpuscles could be distinguished between the cell masses. The boundaries of these channels showed a more or less regular arrangement of the epithelioid cells, which in places had a tendency to become elongated in the direction of the long axis of the blood channel; many of these cells were also present among the corpuscles in the blood spaces. In addition to these spaces with very ill-defined boundaries, other blood channels with more definite walls, usually circular in section, and more resembling capillaries, were present. These channels were bounded by a very delicate sheath, but no endothelium within the sheath could be distinguished. Comparatively few mitoses were observed in any of the sections, so it is probable that the growth was not extending rapidly at the time of examination.

The tumour can obviously be diagnosed as an endothelioma, arising from the endothelium of the blood vessels, and it appears identical in structure, growth, and arrangement of the cells to similar endotheliomata occurring in man.

No metastases were present. 


\section{A FIBRO-SARCOMA OF A PLAICE (PLEURONECTES PLATESSA).}

This tumour was found on a plaice caught at Plymouth, and was brought up to the Laboratory a few hours after death. The fish was a female, 12 inches long, and was in good condition.

The growth consisted of a white ovoid mass situated over the operculum on the ocular surface of the fish. It measured about $\frac{3}{4}$ inch by $\frac{1}{2}$ inch along its longest and shortest axes respectively. It was soft to the touch and was covered with a very delicate epithelial layer containing a few pigment cells. Sections showed that the tumour was a fibro-sarcoma, similar to the fibromata and fibro-sarcomata that are relatively of such common occurrence on the opercula of plaice, but in this case the sarcomatous element prevailed to a much greater extent than usual. No metastases were present.

\section{A TUMOUR OF A WHITING (GADUS MERLANGUS).}

This tumour occurred in a male whiting, measuring 20 inches in length, caught at Plymouth. Its position and relative size are shown in Fig 4. It was soft in consistency, greyish in colour, but flecked with red from the presence of blood-vessels. The surface was bare and uncovered by the cutaneous epithelium. A median incision showed that the tumour arose from the fibrous tissue layer forming the dermis; there was no tendency to invade the subjacent muscles, and no metastases were present.

Sections (Fig. 5) showed that the growth consisted of a uniform reticulum of fine strands of some fibre-like substance, containing a number of small rounded cells with little or no cytoplasm, which were usually arranged along the fibres. These cells were seldom aggregated together into masses, and no mitoses were observed. A few more elongated nuclei resembling those of fibroblasts were seen, and irregular spaces filled with blood corpuscles were present.

At first sight the tumour somewhat resembled a fibrinous exudate of inflammatory origin, but a more careful examination and comparison of the small round cells with the normal leucocytes of the blood of the whiting showed that they had little in common, and the delicate reticulum of which the growth was chiefly composed in reality bears little resemblance to any exudate or tissue produced as an inflammatory reaction.

It seems probable that the tumour arose from a peculiar type of pathological multiplication of connective tissue cells, or fibroblasts, 
and so is perhaps related to the sarcomata, but until more extended observations can be made on other cases, this must remain as the merest surmise.

\section{HAEMANGIOMATA OF A SPOTTED RAY (RAIA MACULATA) AND OF A GURNARD (TRIGLA LINEATA).}

These tumours were accompanied by the presence of parasitic copepods; unfortunately in each case the body of the copepod had been broken off, leaving merely the haustoria imbedded in the growth, so that their species could not be determined.

In the case of the gurnard a small reddish soft tumour was present on the inner surface of the operculum; in the case of the ray, a similar tumour was present on the skin in the mid-ventral line of the body at the level of the fifth gill arch.

Sections showed a condition identical with the capillary Haemangiomata found in man. The tumours consisted of an irregular mass of dilated thin-walled capillaries filled with blood cells: the haustorial branches of the parasites could be easily recognised in the middle of each tumour.

In these cases it is impossible to say whether the tumours developed first, and then were attacked by the parasitic copepods, or whether they represent a peculiar type of reaction on the part of the host to the presence of the parasite. The former alternative would seem the more probable, since in by far the majority of cases of infection by parasitic copepods, little or no sign of an inflammatory reaction on the part of the host is present.

\section{A PIGMENTED TUMOUR OF A MACKEREL (SCOMBER SCOMBER) OF INFLAMMATORY ORIGIN.}

This fish, a male, 11 inches in length, caught at Plymouth, showed a large diffuse swelling on its side, situated about 3 inches from the tail. The surface of the skin was not broken, but was very darkly pigmented.

On cutting through the skin and deep into the subjacent muscular tissue, the cut surface appeared soft, haemorrhagic and degenerated, and was of a brownish colour; in places small black specks, due to the aggregation of pigment granules into masses, were visible to the naked eye. The swelling was not circumscribed, but passed imperceptibly into the surrounding normal muscular tissue: the vertebral column was not affected.

Sections of the diseased area presented an appearance superficially resembling a melanotic sarcoma, so much so that without some 
experience of the histology of inflammation and muscular degeneration in fish, it might very easily be diagnosed as such. The sections showed that there was a great increase in the number of the muscle nuclei, and loss of definite striation of the fibres, followed by atrophy: some increase in the amount of fibrous tissue surrounding the muscle bundles had taken place, and in many cases this thickened muscle sheath was filled only with muscle nuclei and leucocytes, all trace of the muscle itself having disappeared. Fibroblasts in all stages of division were present as well as many leucocytes.

The blood capillaries in the neighbourhood were dilated, and in regions where the inflammatory process was most severe, irregular blood spaces without definite walls were found. The whole of the diseased area was crowded with minute pigment granules, often aggregated into small masses; many of the leucocytes contained large numbers of these pigment granules, but otherwise the granules were always extra-cellular. The skin showed little sign of disease, but contained a few pigment granules in the dermis, deposited in thin layers parallel to the surface; the most intense area of pigmentation was between the dermis and the muscles, where an almost continuous sheet of pigment had been formed.

I have experimentally produced a condition closely resembling this melanotic myositis by long-continued repetition of the application of a strong solution of Iodine to a circumscribed area of the skin of Fundulus heteroclitus. In cases where the irritation due to the Iodine was sufficiently intense to cause inflammation of the subdermal muscular tissue, a condition characterised by atrophy of the muscles, great multiplication of the muscle nuclei, and development of pigment granules, accompanied by the usual phenomena of inflammation, was produced. In this case also the presence of numbers of cells arising by multiplication of the muscle nuclei, together with the pigment granules and leucocytes, gave at first sight a picture suggestive of a sarcomatous growth of a melanotic type.

The particular swelling here described as occurring in a mackerel may thus be considered as a melanotic myositis of unknown cause, and it is perhaps worthy of note that the formation of granules of a pigment apparently resembling melanin can be artificially produced in the tissues of fish by causing mild but continued inflammation.

DESCRIPTION OF PLATE IV.

Illustrating Mr. G. H. Drew's paper on "Some Cases of New Growths in Fish."

Fig. $1 \times \frac{5}{8}$. Photograph of Fibro-sarcoma of Raia macrorhynchus, cut open to show internal surface and origin from perichondrium of one of the fin rays. 
Journ, Mar. Biol. Assoc, Vol IX

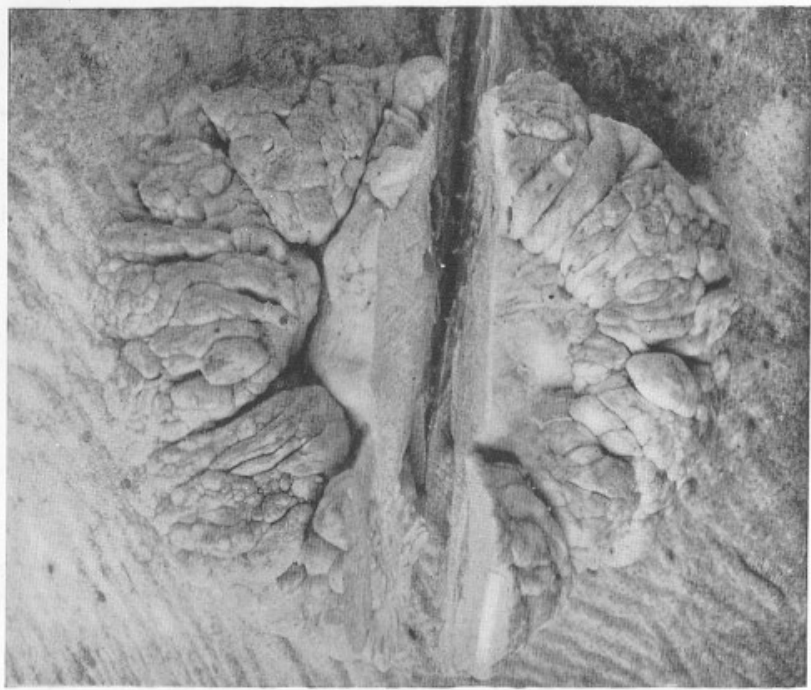

FIG 1 .

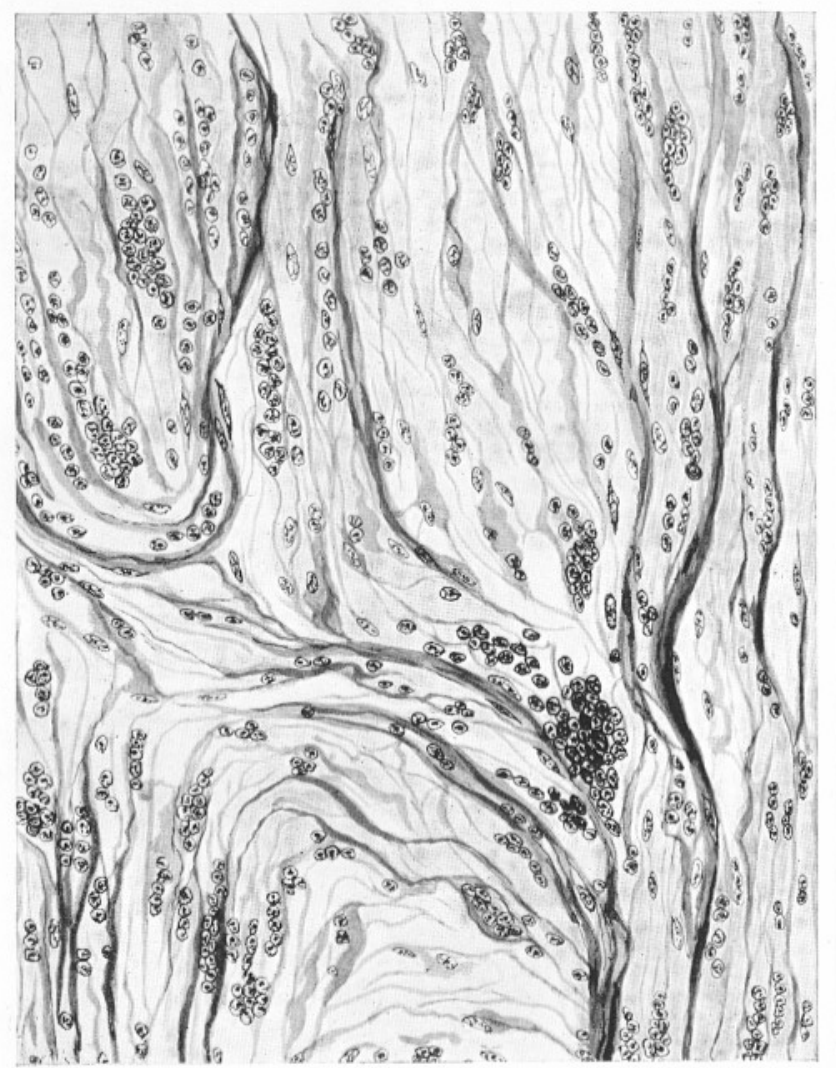

FIG 3 .

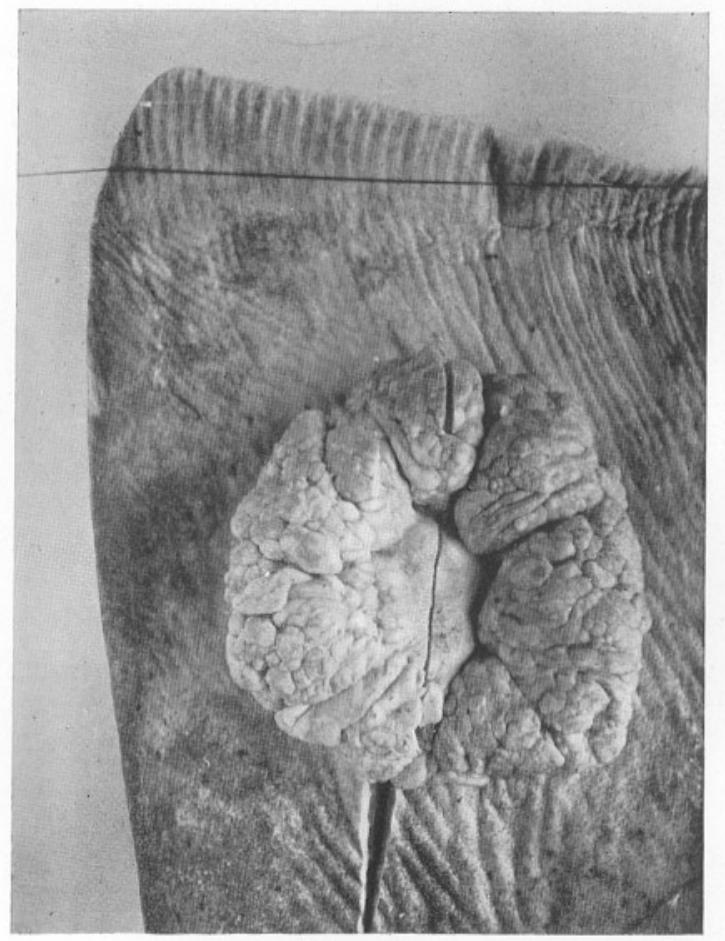

FIG 2.

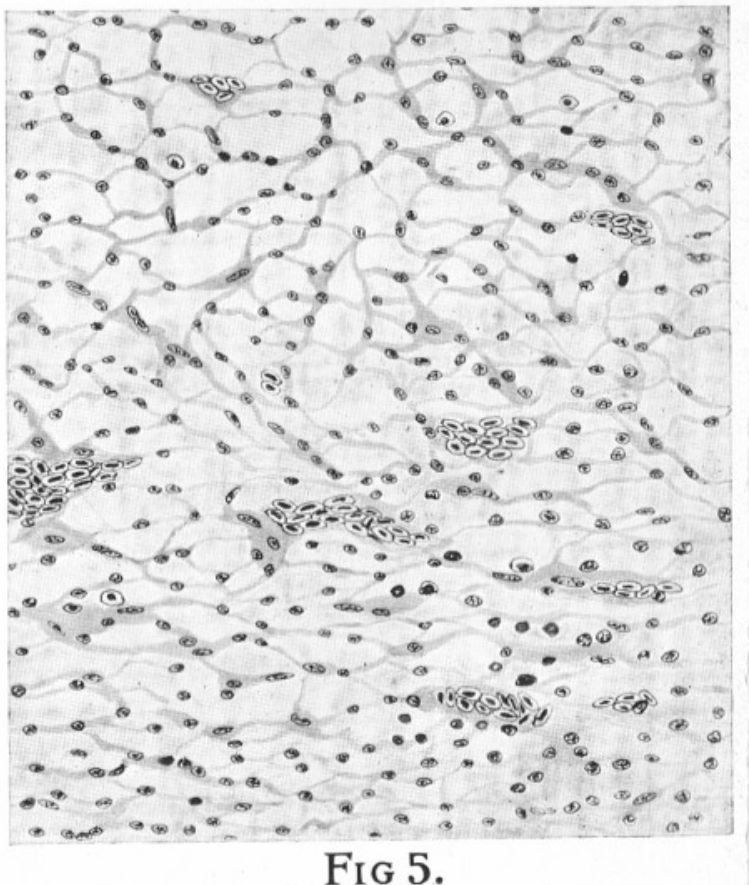

FIG 5.
Plate IV

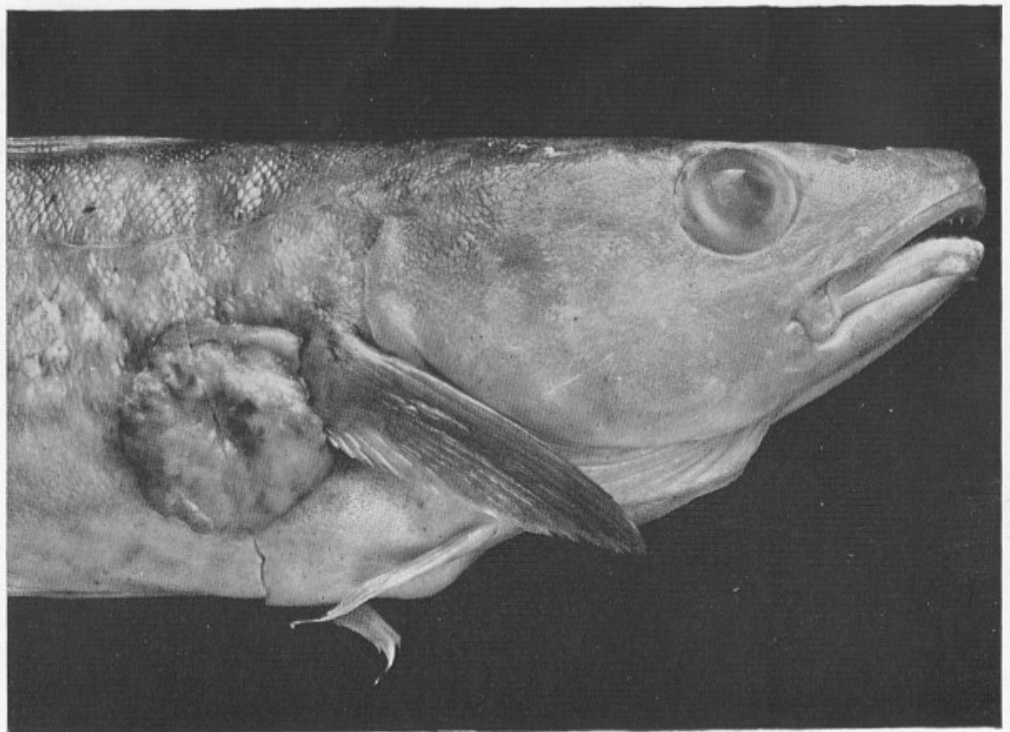

Fig 4.

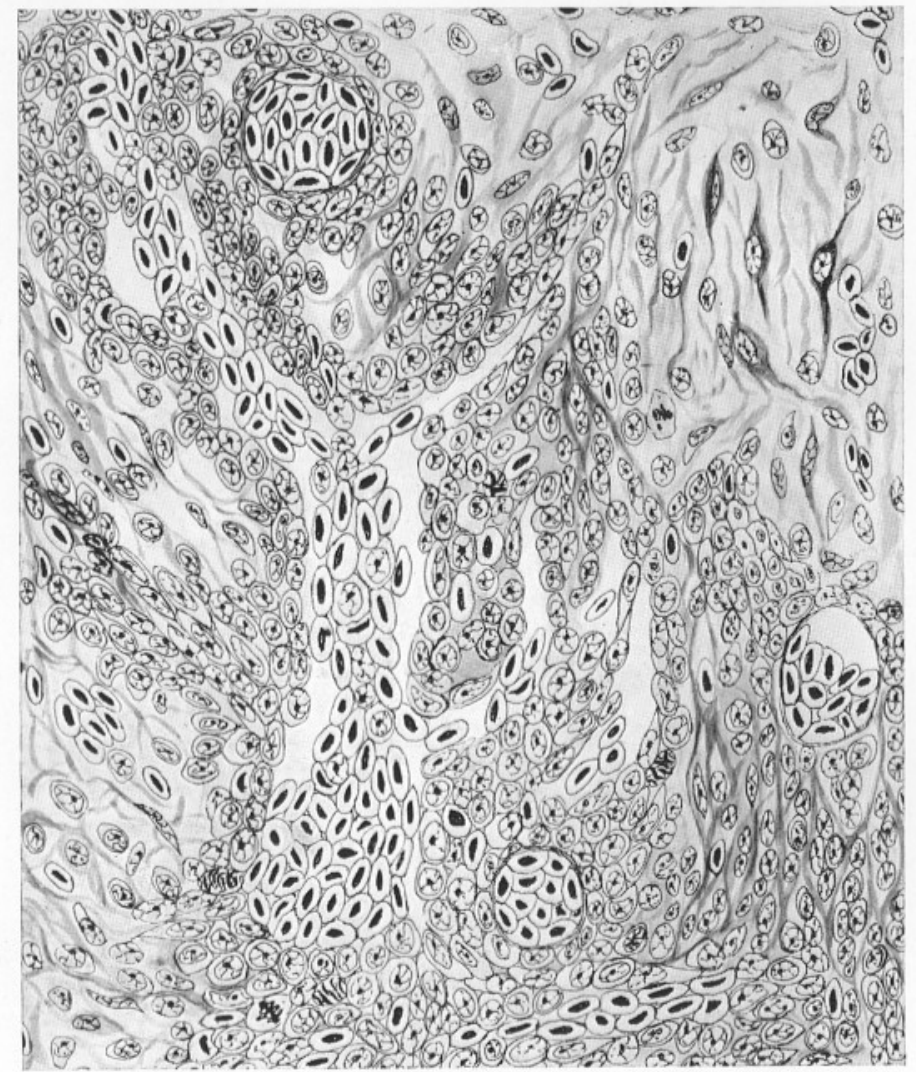
FIG 6 . 
Fig. $2 \times \frac{7}{16}$. As Fig. 1, but showing position of tumour on the fin.

Fig. $3 \times 150$. Section of tumour shown in Figs. 1 and 2. Irregular strands of fibrous tissue are present, with numbers of small round sarcomatous cells.

Fig. $4 \times \frac{1}{2}$. Photograph of Whiting, showing position of the tumour.

Fig. $5 \times 150$. Section of tumour shown in Fig. 4. A fine reticulum of a fibrous nature forms the groundwork of the growth, and small round cells are situated on the strands forming this reticulum. Spaces containing corpuscles are present.

Fig. $6 \times 400$. Section of endothelioma of Eel, Masses of endothelial cells divided by irregular spaces containing blood corpuscles are present, together with some blood spaces with more definite walls.

(N.B.-For the sake of clearness the red blood corpuscles are represented with dense black nuclei, showing none of their nuclear structure.) 